\title{
Associations between white blood cell count, lung function, respiratory illness and mortality: the Busselton Health Study
}

\author{
A.L. James*, M.W. Knuiman ${ }^{+}$, M.L. Divitini ${ }^{+}$, A.W. Musk**, G. Ryan**, H.C. Bartholomew ${ }^{+}$
}

\begin{abstract}
Associations between white blood cell count, lung function, respiratory illness and mortality: the Busselton Health Study. A.L. James, M.W. Knuiman, M.L. Divitini, A.W. Musk, G. Ryan, H.C. Bartholomew. (C) ERS Journals Ltd 1999.

ABSTRACT: An independent association between reduced levels of lung function and increased mortality from nonrespiratory causes has been observed in a number of studies. Since the total white blood cell count (WBC) has been related to both death from coronary heart disease and to levels of lung function, the relationship between these parameters was examined in subjects from the Busselton Health Surveys.

Questionnaires regarding respiratory and cardiac illness and smoking habits were administered and total WBC, forced expiratory volume in one second (FEV1) and forced vital capacity measured in 2,105 males and 2,186 females at their initial attendance at a Busselton Health Survey in 1969, 1972 or 1975. Mortality follow-up to 1995 was completed.

Multiple linear regression showed that smoking, increasing age, reduced FEV1 (\% predicted) and a history of bronchitis were associated with increased WBC. Reduction of FEV1 (\% pred) by $20 \%$, a history of dyspnoea and an increase in WBC of 1,300 cells $\cdot \mathrm{mL}^{-1}$ were predictive of increased mortality from all causes or coronary heart disease by approximately 20,100 and $10 \%$ respectively, independent of smoking. Removing WBC from the regression model did not significantly change the relationship between FEV1 and mortality.

The study shows that the white blood cell count, forced expiratory volume in one second and dyspnoea are independently related to mortality in both males and females and that the effect of forced expiratory volume in one second on mortality is not explained by the white blood cell count.
\end{abstract}

Eur Respir J 1999; 13: 1115-1119.

\begin{abstract}
Depts of *Pulmonary Physiology and **Respiratory Medicine, Sir Charles Gairdner Hospital, Nedlands, Western Australia. ${ }^{+}$Dept of Public Health, University of Western Australia, Western Australia.
\end{abstract}

\section{Correspondence: A. James}

Dept of Pulmonary Physiology

Sir Charles Gairdner Hospital

Verdun Street

Nedlands 6009

Western Australia

Fax: 61893462034

\section{Keywords: Busselton}

lung function

mortality

white blood cells

Received: August 271998

Accepted after revision November 11998
Numerous studies have shown an association between reduced pulmonary function and increased risk of death from all causes [1-4], pulmonary disease [5], coronary heart disease $[4,6,7]$, cardiovascular disease $[8-10]$ and cerebrovascular disease $[11,12]$. The rate of decline of lung function also independently predicts an increased risk of death $[13,14]$. The association of reduced lung function and increased mortality in these studies is independent of sex, age, height, weight, smoking habits or pre-existing cardiovascular disease. The mechanism(s) for the association between lung function and mortality remains unexplained, although may include other factors which are related to both lung function and risk of death. An increased white blood cell count (WBC) has been associated with lower levels of lung function $[15,16]$ and an increased rate of decline of lung function [16, 17], which is only partly explained by smoking habits.

An increased WBC has also been associated with increased risk of myocardial infarction [18]. It is possible that the association between decreased lung function and increased mortality is explained by an increase in the number of white blood cells in the peripheral blood, owing only in part to cigarette smoking. WeIss et al. [19] reported 170 deaths over 30 yrs from 1,956 healthy males in the Normative Aging Study. They found that lung function and WBC independently predicted an increased likelihood of death. In the present study, the association between WBC, lung function, respiratory illness (asthma, bronchitis, wheeze, dyspnoea) and mortality was examined in a cohort of males and females from the general population of a semirural town, followed for up to $25 \mathrm{yrs}$ for mortality. The specific objectives were to investigate whether lung function and respiratory illness were related to the WBC, to establish if WBC is an independent predictor of mortality, and to investigate the extent to which the association between lung function and mortality can be explained by the WBC.

\section{Subjects and methods}

Busselton is a seaside town of Western Australia, with a population of predominantly European origin. Cross-sectional surveys of adults listed on the electoral roll were undertaken at intervals of 3 yrs from 1966 to 1981. Enrolment to vote is compulsory in Australia. This study is based on an analysis of the data from 2,105 males and 2,186 females at the time of their first survey attendance in 1969,1972 or 1975 , who were $25-79$ yrs of age and had available data for all required variables. Participation rates 
for the total adult populations at the times of these studies were 90,86 and $76 \%$, respectively. A wide range of healthrelated data were gathered in each survey including demographic variables, general health and lifestyle variables, health history variables, and physical, biochemical, haematological and immunological measurements. General descriptions of the surveys have been reported previously [ 10 , 20].

Forced expiratory volume in one second (FEV1) and forced vital capacity (FVC) were measured in all three surveys using a McDermott dry spirometer (Pneumoconiosis Research Unit, Penarth, UK). All values obtained were corrected to body temperature and ambient pressure, and saturated with water vapour (BTPS), assuming a fixed room temperature and atmospheric pressure. Results were recorded as the highest of three successive maximum expiratory manoeuvres, provided that two of the recordings were within $10 \%$ of each other. FEV1, as a percentage of predicted was calculated by taking the ratio of measured FEV1 to predicted FEV1. Predicted FEV1 was calculated separately for males and females from linear regressions of FEV1 on age and height derived from the Busselton survey data from 1966 to 1981 and on never smokers without asthma, bronchitis, wheeze, dyspnoea and heart disease. The prediction equations are FEV1 $=-3.33-0.03 \times$ age +4.80 $\times$ height for males, and FEV1 $=-1.87-0.03 \times$ age +3.55 $\times$ height for females. The same method was used to calculate predicted FVC. Respiratory illness was assessed from responses to a self-administered questionnaire based on the British Medical Research Council questionnaire [21]. Participants were asked to report if they had been treated for bronchial asthma (1969 and 1972) or asthma (1975). Bronchitis was defined as cough and/or phlegm production for at least 3 months of the year. Wheeze was defined as a positive response to the question "Does your chest ever sound wheezing or whistling?". Dyspnoea was defined as shortness of breath (and having to stop for breath) when walking on level ground with other people of the same age. Smoking habits were obtained by questionnaire. Subjects were defined as smokers if they had smoked as much as one cigarette per day for $1 \mathrm{yr}$, and all subjects were categorized as either current smokers (smoking at the time of study), exsmokers (previously smoked, but not smoking at the time of study) or neversmokers.

Mortality follow-up from the baseline survey (1969, 1972 or 1975 ) to 1995 was available. Deaths among survey participants were identified by linkage to the death register for Western Australia and through relatives. Survival status was confirmed by linkage to the electoral roll and Telecom telephone directory, and through relatives. The length of follow-up ranged from 20 yrs for the 1975 survey participants to 26 yrs for the 1969 survey participants.

As the distribution of WBC was positively skewed, the natural logarithm $(\ln )$ of WBC was used in all analyses. Multiple linear regression was used to investigate the associations between lung function and respiratory illness and WBC after adjustment for age and smoking status. Cox proportional hazard regression was used to assess the relationship between $\mathrm{WBC}, \mathrm{FEV} 1 \%$ predicted, respiratory symptoms and mortality after adjusting for age and smoking [22]. The effects of WBC, FEV1 \% pred, and respiratory illness on mortality were expressed as hazard ratios (relative risks). If the $95 \%$ confidence interval for the hazard ratio excludes 1.0 then the estimated hazard ratio is statistically significant at the $5 \%$ level (i.e. p-value $<0.05$ ). The survival time was the time (in yrs) from the baseline survey $(1969,1972$ or 1975) to death or last date known to be alive (usually December 31, 1995). Individuals who had not died were considered censored. The SAS software package (SAS Institutes, Cary, NC, USA) was used to carry out the calculations [23].

\section{Results}

The baseline characteristics of the 2,105 males and 2,186 females are given in table 1 . The mean age was 49 yrs (range 25-79 yrs) for both males and females, 5\% of males and 5\% of females reported having had asthma ever, $19 \%$ of males and $9 \%$ of females reported having bronchitis (persistent cough or phlegm), 11\% of males and $5 \%$ of females reported having wheeze, and $3 \%$ of males and $4 \%$ of females reported having dyspnoea. A total of $45 \%$ of males and $24 \%$ of females were smokers at their baseline study. For males, the mean \pm SD total WBC $\left(\times 1,000\right.$ cells $\left.\cdot \mathrm{mL}^{-1}\right)$ was $6.30 \pm 1.57$ for never-smokers, $6.41 \pm 1.53$ for exsmokers and $7.87 \pm 1.98$ for current smokers. For females the corresponding values were $6.37 \pm$ $1.68,6.37 \pm 1.59$ and $7.40 \pm 1.90$, respectively. A total of 837 males and 645 females died during the follow-up period. Specific causes of death for males included cardiovascular (51\% of total), cancer $(26 \%)$ and respiratory $(9 \%)$. The corresponding values for females were 56, 24 and $5 \%$, respectively.

Table 2 shows the effect of FEV1 \% pred, asthma, bronchitis, wheeze, and dyspnoea on $\ln \left(\mathrm{WBC} \cdot 1,000 \mathrm{cells}^{-1}\right.$ ) after adjustment for age and smoking. Among both males and females, FEV1 \% pred (negatively), bronchitis (positively) and wheeze (positively) were significantly related to WBC. When all variables were entered into the regression model simultaneously, FEV1 \% pred (negatively) and bronchitis (positively) remained significant in both males and females, and hence, were independent predictors of WBC after adjustment for age and smoking.

Table 1. - Characteristics of subjects at initial assessment

\begin{tabular}{lcc}
\hline & Males & Females \\
\hline Subjects n & 2105 & 2186 \\
Age yrs & $49.2 \pm 14.7$ & $48.8 \pm 14.1$ \\
FEV1 L & $3.32 \pm 0.91$ & $2.36 \pm 0.64$ \\
FVC L & $4.56 \pm 0.95$ & $3.13 \pm 0.72$ \\
FEV1 \% pred & $94.8 \pm 18.3$ & $99.6 \pm 18.4$ \\
Asthma & 4.8 & 4.6 \\
Bronchitis & 18.7 & 9.5 \\
Wheeze & 11.1 & 4.6 \\
Dyspnoea & 2.9 & 4.0 \\
Smoking & & \\
Never & 26.9 & 64.3 \\
Ex & 27.9 & 11.9 \\
Current & 45.2 & 23.7 \\
WBC $\times 1000$ cells $\cdot \mathrm{mL}^{-1}$ & $7.04 \pm 1.91$ & $6.62 \pm 1.78$ \\
Ln $\left(\right.$ WBC· 1000 cells $^{-1}$ ) & $1.92 \pm 0.27$ & $1.86 \pm 0.27$ \\
\hline Data presen & &
\end{tabular}

Data are presented as mean \pm SD or percentages. FEV1: forced expiratory volume in one second; FVC: forced vital capacity; WBC: white blood cell count. 
Table 2. - Univariate effects of forced expiratory volume in one second (FEV1) \% predicted, asthma, bronchitis, wheeze and dyspnoea on In(white blood cell count 1,000 cells $^{-1}$ ) after adjustment for age (in yrs) and smoking (never, ex, current)

\begin{tabular}{|c|c|c|c|c|c|c|}
\hline \multirow[b]{2}{*}{ Variable } & \multicolumn{2}{|c|}{ Males } & \multicolumn{2}{|c|}{ Females } & \multicolumn{2}{|c|}{ Overall } \\
\hline & Coefficient (SEM) & p-value & Coefficient (SEM) & p-value & Coefficient (SEM) & p-value \\
\hline FEV1 \% pred* & $-0.025(0.006)$ & $<0.001$ & $-0.029(0.006)$ & $<0.001$ & $-0.027(0.004)$ & $<0.001$ \\
\hline Asthma & $0.007(0.025)$ & 0.782 & $0.040(0.026)$ & 0.122 & $0.023(0.018)$ & 0.191 \\
\hline Bronchitis & $0.083(0.014)$ & $<0.001$ & $0.058(0.019)$ & 0.002 & $0.074(0.011)$ & $<0.001$ \\
\hline Wheeze & $0.043(0.017)$ & 0.014 & $0.078(0.026)$ & 0.003 & $0.054(0.015)$ & $<0.001$ \\
\hline Dyspnoea & $0.044(0.032)$ & 0.175 & $0.016(0.028)$ & 0.578 & $0.027(0.021)$ & 0.199 \\
\hline
\end{tabular}

*: Effect for a change of $20 \%$ in predicted FEV1.

Investigation of interactions with smoking status showed that the effects of FEV1\% pred and bronchitis on WBC were the same for never-smokers, exsmokers and current smokers.

Table 3 shows the hazard ratios (age and smoking adjusted) for the effects of FEV $1 \%$ pred, asthma, bronchitis, wheeze, dyspnoea and $\ln \left(\mathrm{WBC} \cdot 1,000\right.$ cells $\left.^{-1}\right)$ in the fitted Cox regression models for all cause mortality. For both males and females, FEV1 \% pred, dyspnoea and WBC are significantly and independently predictive of mortality. The hazard ratios are similar for males and females. An increase of $20 \%$ in FEV1 \% pred is associated with a decrease of $\sim 20 \%$ in the mortality rate, the presence of dyspnoea approximately doubles the mortality rate, and an increase of 0.2 in $\ln \left(\mathrm{WBC} \cdot 1,000\right.$ cells $\left.^{-1}\right)$, which is equivalent to an increase of $\sim 1,300$ in $\mathrm{WBC}$, is associated with an increase of $\sim 10 \%$ in the mortality rate. Investigation of interactions with smoking showed that the effect of WBC on mortality was similar for never-smokers, exsmokers and current smokers. When WBC is omitted from the regression model, the hazard ratio for $\mathrm{FEV} 1 \%$ pred is about the same, indicating that WBC does not explain the association between $\mathrm{FEV}_{1} \%$ pred and mortality.

Separate analyses using FVC (as a percentage of the predicted value, using Busselton data) or the FEV1/FVC ratio also showed that lung function, dyspnoea and WBC were independently associated with an increased mortality, in both males and females. The findings were essentially the same when death from coronary heart disease was used as the outcome, although the hazard ratio for WBC increased from $\sim 1.10$ to $\sim 1.14$. For cancer, the effect of FEV1 was similar to all cause mortality, but the effect of the WBC was very small and not significant. The number of cases of respiratory death was too small for accurate analysis.

\section{Discussion}

This study shows that FEV1 (as a percentage of the predicted value) and bronchitis are both independently related to the $\mathrm{WBC}$, that all cause mortality and death from coronary heart disease are related to $\mathrm{FEV} 1, \mathrm{WBC}$ and dyspnoea, and that all these relationships are independent of smoking status. However, the relationship between FEV1 and mortality is not explained by the WBC.

Many studies have observed an association between lung function and all cause (including nonrespiratory) mortality $[1-6,8,9,11-14]$. Possible mechanisms for this association include reduced lung function owing to diseases which result in death such as congestive cardiac failure, or illness resulting in both reduced lung function and increased risk of death from cardiac causes, such as sleep apnoea. These explanations seem unlikely, since reduced lung function predicts an increased risk of death

Table 3. - Joint effects of forced expiratory volume in one second (FEV 1 ) \% predicted, asthma, bronchitis, wheeze, dyspnoea and $\ln \left(\right.$ white blood cell count (WBC) 1,000 cells $^{-1}$ ) on mortality after adjusting for age (in yrs) and smoking (never, ex, current)

\begin{tabular}{|c|c|c|c|c|c|c|}
\hline \multirow[b]{2}{*}{ Variable } & \multicolumn{2}{|c|}{ Males } & \multicolumn{2}{|c|}{ Females } & \multicolumn{2}{|c|}{ Overall } \\
\hline & Hazard ratio & $95 \% \mathrm{CI}$ & Hazard ratio & $95 \mathrm{CI}$ & Hazard ratio & $95 \% \mathrm{CI}$ \\
\hline Sex Male & & & & & $3.48^{*}$ & $1.88-6.46$ \\
\hline \multicolumn{7}{|l|}{ Age yrs } \\
\hline Male & $1.65^{*}$ & $(1.59-1.71)$ & & & $1.65^{*}$ & $(1.60-1.71)$ \\
\hline Female & & & $1.80^{*}$ & $(1.73-1.88)$ & $1.79 *$ & $(1.72-1.86)$ \\
\hline \multicolumn{7}{|l|}{ Smoking } \\
\hline Never & 1.00 & & 1.00 & & 1.00 & \\
\hline Ex & 0.96 & $(0.78-1.17)$ & 1.07 & $(0.83-1.39)$ & 1.10 & $(0.86-1.18)$ \\
\hline Current & $1.29 *$ & $(1.04-1.58)$ & $1.39 *$ & $(1.15-1.69)$ & $1.36^{*}$ & $(1.18-1.56)$ \\
\hline FEV1 \% pred & $0.79 *$ & $(0.73-0.85)$ & $0.80^{*}$ & $(0.74-0.86)$ & $0.79 *$ & $(0.75-0.84)$ \\
\hline Asthma & 0.88 & $(0.61-1.25)$ & 1.08 & $(0.73-1.61)$ & 0.97 & $(0.74-1.26)$ \\
\hline Bronchitis & 1.11 & $(0.93-1.32)$ & 1.21 & $(0.95-1.54)$ & 1.15 & $(0.99-1.32)$ \\
\hline Wheeze & 0.99 & $(0.80-1.22)$ & 0.68 & $(0.46-1.02)$ & 0.91 & $(0.76-1.09)$ \\
\hline Dyspnoea & $2.03^{*}$ & $(1.50-2.75)$ & $1.76^{*}$ & $(1.32-2.35)$ & $1.90^{*}$ & $(1.54-2.34)$ \\
\hline $\operatorname{Ln}\left(\mathrm{WBC} \cdot 1000\right.$ cells $\left.^{-1}\right)$ & $1.09^{*}$ & $(1.02-1.15)$ & $1.09^{*}$ & $(1.02-1.16)$ & $1.09 *$ & $(1.04-1.13)$ \\
\hline
\end{tabular}

The hazard ratio for FEV1 \% pred corresponds to an increase of $20 \%$, the hazard ratio for WBC corresponds to an increase of 0.2 in $1 n$ $\left(\mathrm{WBC} \cdot 1,000 \mathrm{cells}^{-1}\right)$ and the hazard ratio for age corresponds to an increase of 5 yrs. CI: confidence interval. *: p<0.05. 
many years before death and long before the clinical development of the disease causing death, and risk factors (weight, smoking, lipid profiles) for diseases such as heart disease or sleep apnoea do not account for the relationship between the level of lung function and the risk of death.

Another explanation for the relationship between the level of lung function and the risk of death is that both are related to a third factor which is determined by genetic/ environmental influences. It is hypothesized that this may be the WBC in the peripheral blood, since previous studies have shown separate associations between cigarette smoking and WBC, cigarette smoking and lung function, WBC and lung function and WBC and risk of death or coronary heart disease (see below). Cigarette smoking is associated with reduced levels of lung function and increased numbers of white cells in the peripheral blood [15] and in the lung [24]. Mortality from respiratory illness, particularly chronic obstructive lung disease and lung cancer, and from cardiovascular disease, is greatly increased in smokers, and smoking is associated with an accelerated decline in lung function with time [25-27]. The association of smoking with reduced lung function and respiratory illness has been attributed to the damaging effects of white blood cells, particularly neutrophils, on lung tissue [28]. This is supported by the association of increased WBCs with reduced levels of lung function and an increased rate of decline in lung function [15, 16], although in these studies the relationship between lung function and WBC is independent of smoking status.

The present study demonstrates a relationship between the $\mathrm{WBC}$ and mortality from any cause or from coronary heart disease. An increase in the WBC of 1,300 cells $\mathrm{mL}^{-1}$ is associated with an increase of $9 \%$ in the risk of death from any cause for both males and females. The association between $\mathrm{WBC}$ and mortality observed in the present study was independent of smoking, age, height, respiratory illness, and lung function. A number of other studies have shown a relationship between the $\mathrm{WBC}$ and increased risk of death [29-32]. The National Health and Nutrition Examination Survey (NHANES 1) study [30] showed that in males, a WBC $>8,100$ cells $\cdot \mathrm{mm}^{-3}$ was associated with a risk ratio of 1.43 for all-cause mortality and of 1.66 for death from coronory heart disease, compared with a WBC $<6,600$ cells $\cdot \mathrm{mm}^{-3}$. This effect was not observed in females. Similar results were seen in studies which included only males, after adjustments for age and smoking habits, both in the UK [31] and the USA [32]. The present study showed an effect of WBC in both males and females.

Mechanisms by which an increased WBC results in an increased risk of death remain to be determined. Possibilities include increased tissue damage due to the release of destructive enzymes from white cells, as is thought to occur in the development of emphysema in smokers [28], or the release of highly reactive oxygen species causing widespread tissue damage $[33,34]$. There is evidence that an imbalance between oxidative stress and antioxidant systems may be important in the development of both respiratory [35] and cardiovascular disease [36]. Therefore, factors which alter the number of white cells (sources of oxidative stress) in the peripheral blood may influence mortality. Constitutional (genetic) factors, and acquired factors such as exposure to allergens, irritants or infec- tions may all be important in determining the WBC over short or long periods. The observations of an association between the blood monocyte count with an increased risk for coronary artery disease [37] and increased blood eosinophils with an increased mortality [38], may reflect different inflammatory mechanisms contributing to both a total increase in white cells and an increased risk of disease and death.

In the present study, it was hypothesized that the WBC might account for the association between reduced lung function and increased mortality from respiratory and nonrespiratory causes. Analysis of 170 deaths over 30 yrs from the Normative Aging Study [19] showed that WBC and FEV1 independently predicted death. The study was conducted after exclusion of those with known cardiac, thyroid, renal or hepatic dysfunction or diabetes. The present study included all attendees and analysed a greater number of deaths in both males and females. In addition to FEV1 and WBC it was also demonstrated that dyspnoea, possibly reflecting existing disease, independently predicts mortality. The analysis shows that lung function, $\mathrm{WBC}$ and dyspnoea are all independent risk factors for mortality, since inclusion of WBC in the regression model makes little difference to the hazard ratio for lung func-tion expressed as FEV1 \% pred, FVC \% pred or $\mathrm{FEV} 1 / \mathrm{FVC}$. Therefore, it must be postulated that separate fac-tors account for the association between increased mor-tality and reduced lung function on the one hand, and increased mortality and $\mathrm{WBC}$ on the other. Other factors which may partly determine the WBC, lung function and mortality may include inflammatory stimuli such as al-lergens, irritants and infections. An association between antibody titres to infectious agents and lung function has been observed [39], but there are no studies relating infections to mortality and lung function or WBC.

The Busselton population is uniform with regard to race, and has minimal environmental exposures such as air pollution or occupations known to impose a risk to respiratory health. Studies of infectious agents in relation to mortality or lung functions have not been undertaken in this population to date.

\footnotetext{
Acknowledgements. The authors thank the Busselton Population Medical Research Foundation for access to the survey data and the community of Busselton for their long-standing cooperation and support for the Busselton Health Study.
}

\section{References}

1. Olofson J, Skoogh BE, Bake B, Svardsudd K. Mortality related to smoking habits, respiratory symptoms and lung function. Eur J Respir Dis 1987; 71: 69-76.

2. Tockman MS, Comstock GW. Respiratory factors and mortality: longitudinal studies in Washington County, Maryland. Am Rev Respir Dis 1989; 140: S56-S63.

3. Beatty TH, Cohen BH, Newell CA, Menkes HA, Diamond EL, Chen CJ. Impaired pulmonary function as a risk factor for mortality. Am J Epidemiol 1982; 116: 102113. 
4. Kryzanowski M, Wysocki M. The relation of thirteenyear mortality to ventilatory impairment and other respiratory symptoms: the Cracow study. Int $J$ Epidemiol 1986; 15: 56-64.

5. Lang P, Nyboe J, Appleyard M, Jensen G, Schnohr P. Ventilatory impairment and chronic mucus hypersecretion as predictors of death from lung cancer. Am Rev Respir Dis 1990; 141: 613-617.

6. Dawber TR, Kannel WB, Friedman GD. Vital capacity, physical activity, and coronary heart disease. In: Raab W, ed. Prevention of Ischemic Heart Disease. Springfield, IL, Charles C Thomas, 1966; pp. 254-265.

7. Friedman GD, Slegelaub AB, Seltzer CC, Feldman R, Collen MF. Smoking habits and the leucocyte count. Arch Environ Health 1973; 26: 137-143.

8. Persson C. Peak expiratory flow rate and risk of cardiovascular disease and death: a 12 year follow-up of participants in the population study of women in Gothenburg, Sweden. Am J Epidemiol 1986; 124: 942-948.

9. Kannel WB, Hubert H, Lew EA. Vital capacity as a predictor of cardiovascular disease: the Framingham study. Am Heart J 1983; 105: 311-315.

10. Cullen KJ, Stenhouse NS, Wearne KL, Welborn TA. Multiple regression analysis of risk factors for cardiovascular disease and cancer mortality in Busselton, Western Australia - a 13 year study. J Chron Dis 1983; 36: 371-377.

11. Welin L, Svardsudd K, Wilhelmsen L, Larsson B, Tibblin G. Risk factors for stroke in a cohort of men born in 1913. $N$ Engl J Med 1987; 317: 521-526.

12. Strachan DP. Ventilatory function as a predictor of fatal stroke. Br Med J 1991; 302: 84-87.

13. Tockman MS, Pearson JD, Fleg JL. Rapid decline in FEV1 - a new risk factor for coronary heart disease mortality. Am J Respir Crit Care Med 1995; 151: 390398.

14. Rodriguez BL, Masaki K, Burchfield C, et al. Pulmonary function decline and 17-year total mortality: the Honolulu heart program. Am J Epidemol 1994; 140: 398-408.

15. Chan-Yeung M, DyBuncio A. Leucocyte count, smoking and lung function. Am J Med 1984; 76: 31-37.

16. Sparrow D, Glynn RJ, Cohen M, Weiss ST. The relationship of the peripheral leucocyte count and cigarette smoking to pulmonary function among adult men. Chest 1984; 86: 383-386.

17. Chan-Yeung M, Abboud R, DyBuncio A, Vedal S. Peripheral leucocyte count and longitudinal decline in lung function. Thorax 1988; 43: 462-466.

18. Friedman GD, Klatsky AL, Siegelaub AB. The leukocyte count as a predictor of myocardial infarction. $N$ Engl $J$ Med 1974; 290: 1275-1278.

19. Weiss ST, Segal MR, Sparrow D, Wager C. Relation of peripheral blood leukocyte count to total mortality, the Normative Aging Study. Am J Epidemiol 1995; 142: 493498.

20. Knuiman MW, Jamrozik K, Welborn TA, Bulsara MK, Divitni ML, Whittall DE. Age and secular trends in risk factors for cardiovascular disease in Busselton. Aust $J$ Public Health 1995; 19: 375-382.

21. Medical Research Council. Committee on the aetiology of chronic bronchitis: standardised questionaire on respiratory symptoms. $\mathrm{Br}$ Med $J$ 1960; ii: 1665 .
22. Kalbfleisch JD, Prentice RL. The Statistical Analysis of Failure Time Data. New York, Wiley, 1980.

23. SAS STAT Software. Changes and Enhancement Through Release 6.12. SAS Institute Inc, NC, 1997.

24. MacNee W, Wiggs B, Belzberg AS, Hogg JC. The effects of cigarette smoking on neutrophil kinetics in human lungs. N Engl J Med 1989; 321: 924-928.

25. Peat J, Woolcock AJ, Cullen K. Decline of lung function and development of chronic airflow limitation: a longitudinal study of non-smokers and smokers in Busselton, Western Australia. Thorax 1990; 45: 32-37.

26. Anthonisen NR, Connett JE, Kiley JPr. Effects of smoking intervention and the use of an inhaled anticholinergic bronchodilator on the rate of decline of FEV1. The Lung Health Study. Am Rev Respir Dis 1994; 272: 1539-1541.

27. Burchfiel CM, Marcus EB, Curb JD, et al. Effects of smoking cessation on longitudinal decline in pulmonary function. Am J Respir Crit Care Med 1995; 151: 17781785.

28. Janoff A. Biochemical links between cigarette smoking and pulmonary emphysema. J Appl Physiol 1993; 55: 285-293.

29. Nieto FJ, Szklo M, Folsom AR, Rock R, Mercuri M. Leukocyte count correlates in middle-aged adults: the atherosclerosis risk in communties (ARIC) study. $\mathrm{Am} \mathrm{J}$ Epidemiol 1992; 136: 525-537.

30. Gillum RF, Ingram DD, Maktuc DM. White blood cell count, coronary heart disease, and death: the NHANES 1 epidemiologic follow-up study. Am Heart $J$ 1993; 125 : 855-863.

31. Grimm RHJ, Neaton JD, Ludwig W. Prognostic importance of the white blood cell count for coronary, cancer and all-cause mortality. JAMA 1985; 254: 1932-1937.

32. de Labry LO, Campion EW, Glymm RJ, Vokanas PS. White blood cell count as a predictor of mortality: results over 18 years from the normative aging study. J Clin Epidemiol 1990; 43: 153-157.

33. Babior BM. The respiratory burst of phagocytes. J Clin Immunol 1984; 73: 599-601.

34. Suematou M, Schmid-Schankein GW, Chavez-Chavez $\mathrm{RH}$, et al. In vivo visualization of oxidative changes in microvessels during neutrophil activation. Am J Physiol 1993; 264: H881-H891.

35. Schwartz J, Weiss ST. Dietary factors and their relation to respiratory symptoms: NHANES 11. Am J Epidemiol 1990; 132: 67-76.

36. Epstein FH, Diaz MN, Frei B, Vita JA, Keaney JF. Antioxidants and atherosclerotic heart disease. $N$ Engl J Med 1997; 337: 408-416.

37. Olivares R, Ducimetiere P, Claude JR. Monocyte count: a risk factor for coronary heart disease? Am J Epidemiol 1993; 137: 49-53.

38. Hospers JJ, Schouten JP, Postma DS, Rijcken B. Eosinophilia is an independent risk factor for mortality in the population. Am J Respir Crit Care Med 1997; 155: A83.

39. Omenaas E, Bakke P, Eide GE, Haukenes G, Gulsvik A. Serum respiratory virus antibodies: predictor of reduced one-second forced expiratory volume (FEV1) in Norwegian adults. Int $J$ Epidemiol 1996; 25: 134-141. 